\title{
Stunning artwork adorns new London facility
}

The Eastman Dental Hospital's new UCLH home opened on 8 October in Huntley Street, behind London's Tottenham Court Road. The $£ 100$ million hospital is one of the biggest specialist centres in Europe for dental, ear, nose, throat, hearing and balance services. It brings the Eastman and the Royal National Throat, Nose and Ear Hospital together under one roof, close to the main UCLH campus.

A distinctive feature of the new building is floor to ceiling artwork around the lift lobbies and continuing into treatment spaces

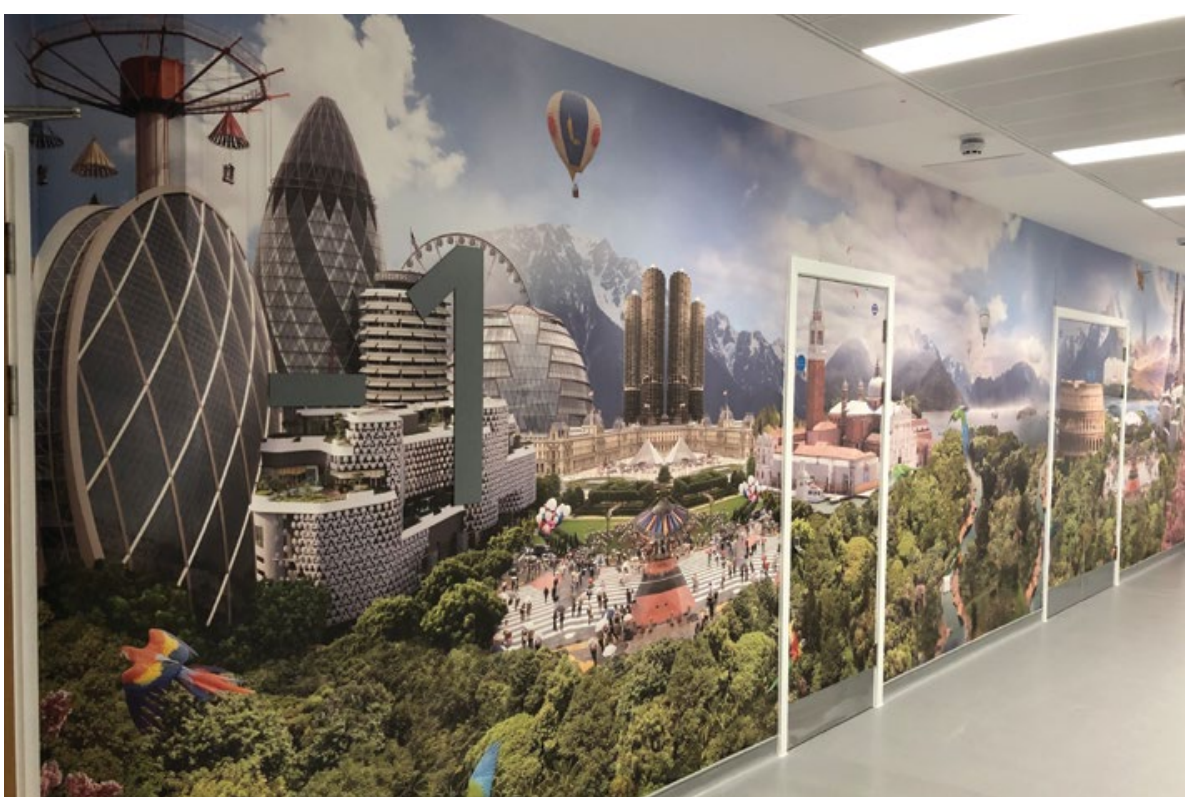

and some of the consulting rooms. The designs make the building welcoming and calming and were the work of artists whose fees, $£ 64,000$, were funded by the Friends of UCLH, a small charity.

Diana Scarrott, Chair of the Friends, said: 'Our charity pays for "extras" - things that are "nice to have" that the NHS can't afford or doesn't fund. We were delighted to be able to help the Eastman's new building by paying its commissioned artists. We hope dentists and patients will love them'.

If you would like to support the Friends it's easy to join online. Search for 'Friends of UCLH' and the charity comes to the top of the list. Membership costs $£ 2$ per month - ' less than a monthly coffee' as the Friends put it.

Diana said: 'The Friends aren't a specifically dental charity - we work across all of UCLH. But we would love to have more dentist Friends in our membership, keeping an eye on what we do and making sure that we respond to dental needs. If you would like to get in touch with the Friends to talk about a donation, email uclh. friendsofuclh@nhs.net.

\section{Here has been an advertisement.}

\section{SPRINGERNATURE}

